\title{
Optimal Sales Discount Decision Model with Fixed Ordered Quantities
}

\author{
Shi ZHENG \\ School of Economics and Management, Dalian Nationalities University, Dalian 116600, China \\ E-mail: zhengshi1993@126.com \\ Wen ZHENG \\ School of Economic and Trading, North-eastern University in Qinhuangdao, Qinhuangdao 066004, \\ China \\ E-mail: reseacherzw@126.com
}

\begin{abstract}
The purpose of this paper is to study sales pricing and discount strategy for sellers. Here, the suppliers require fixed order quantities to the sellers. Therefore, to incorporate the concept of sellers' maximum profit and sales discount into the model, the author classifies the multi-category goods into backlog, flat and profitable one. Then the model to determine the optimal sales price strategy for a sales discount decision system with fixed order quantities is analyzed. As most of the non-linear model can be linearization, a mathematical model for sales discount decision system is developed when demand rate is a liner function of the sales price. By analyzing the total profit function, the authors developed some useful results to characterize the optimal solution and provided a method to find the sales discount for holdovers. By developing a solution algorithm, the optimal retail price and sales discount for holdovers are provided. Case scenarios are presented to validate the proposed model. Through case scenarios analyses, it is observed that optimal sales discount can help the sellers earn maximum profit with constraints of fixed order quantities. Most of the research articles available in the literature assumed that the sellers are always in optimal situation. In fact, sellers' decisions rely on suppliers' decisions in most cases. In this paper, determination of sales discounts can be seen as sellers compromise to suppliers by seeking the optimal strategy with downstream customers. In view of this fact, a mathematical model is developed considering sales price dependent linear demand and sellers' profit. Very few researchers have investigated optimal sales discount decision system with fixed order quantities; although it is a real situation the sellers should be faced.
\end{abstract}

Keywords EOQ model; sales discount; decision model; sellers; suppliers

\section{Introduction}

When management experts solve the problems relevant to the EOQ model, they tend to forget "the other side of the coin". This situation often appears in the actual operation, i.e. when the order quantity is fixed, how to determine the sales discounts. The Economic Order Quantity (EOQ) formula is one of the most pervasive formulas in the business and engineering literature. In fact, every business should have a certain model or inventory management system.

Received November 21, 2013, accepted May 2, 2014 
For example, Hewlett-Packard developed inventory replenishment strategies in collaboration with retailer; IBM is developing an inventory management strategy. However, no common inventory management strategy is suitable for all businesses. Thus, although the inventory theory (also known as storage theory) has been introduced to business area for nearly a century, it is still a hot issue. How to form their own set of strategies is always a key issue related to their development for many SMEs (Small and Medium Enterprises) in developing countries. EOQ model was originally conceptualized by Harris in $1915^{[1]}$. Minimizing the total cost becomes the main line in the researches of inventory EOQ models ${ }^{[2-7]}$. These studies lay the foundation for the EOQ research and enable it more widely practical application. The only drawback is that they make some of the later ones produced the illusion that the commodity prices has nothing to do with optimal order quantity. This illusion stems from the basic assumptions and implicit assumptions, the objective function, the model classification, and many other causes in EOQ model and the expanded ones. The determination of the objective function is particularly important in constructing the EOQ model. The objective function only including cost to sellers or costs of suppliers and sellers is open to question. While the interests of suppliers and sellers sometimes are unified. However, in most cases, there is unbridgeable contradiction between them. For example, a supplier hopes that the unit-price discounts or other discounts can boost profits, and then the sellers will increase costs in such case. The earliest discussion about the possibility to improve the profits and reduce costs of suppliers and sellers is Crowther ${ }^{[8]}$. He employed a price discount system to realize this possibility. In addition, incremental discounts EOQ mode ${ }^{[9-10]}$ analyzed the contradictions between the supplier and suppliers from the sellers' point of view. Banerjee ${ }^{[11]}$ chosen inventory cost of suppliers and sellers as the objective function. He established a joint economic lot decision model. The impact of price and order quantity on cost is discussed in detail in the model. This study will follow the research paradigm from sellers' perspective. How to reduce the backlog of merchandiser inventory by making sales' discount, and make goods inventory always in a relatively reasonable level? This is a question will be answered in this paper. Therefore, the discounts in this paper are refers sales discounts; the price discounts from supplier perspectives are completely different concepts. This paper is organized as follows, Section 1 contains problem raised, the main contribution of this paper and a review of relevant research; Section 2 discusses sales discount decision problem under the fixed economic order quantity; Section 3 presents a case study; Section 4 makes the model discussion; Section 5 is the conclusion.

\subsection{Overview of results}

A major finding in this paper is that the sellers can increase sales by sales discounts, to realize maximize profits according to the demand rate and enable the category of goods inventory always in a relatively reasonable level. This paper shows that sales discounts can be determined under the fixed order quantity by taking demands as a "bridge". It breaks the assumption that sellers is always in the optimal state.

\section{$1.2 \quad$ Literature review}

The assumption that sellers are always in the optimal state plays a crucial role in most researches relevant to the EOQ model. Then, the key question is how the suppliers can 
make biggest profit by their own price discounts strategy ${ }^{[12]}$. This assumption is questionable. Michael Porter's diamond model has used the concept of bargaining power. It reveals the contradictions between suppliers and sellers comprehensively. In addition, there are other challenges to the traditional EOQ model, such as time-varying demand and cost issues (i.e., deterministic problems of discrete-time non-homogeneous inventory system in finite stage); adjustment supplementary strategic issues; supplementary costs subtle changes issue; the demand rate issues and so on.

Goyal et al. ${ }^{[13]}$ pointed out that "Many researchers have assumed that the sales price and the purchase cost is the same, this is a disadvantage for the development of various types of EOQ model". They also designed a kind of algorithm for sellers to determine the optimal prices and quantities simultaneously.

In fact, the issue on combination of inventory control and pricing ${ }^{[14-15]}$ is a classical one. A single-stage model is a starting point of this issue, which simply determines a unique price and economic order quantity. Subsequently, some scholars discuss the cost and uncertainty demand, equilibrium conditions under single-stage, and the increased or decreased marginal cost. A preliminary analysis of joint decision on the multi-stage storage/pricing model was also made ${ }^{[16-17]}$. After that, Karlin and Carr ${ }^{[18]}$ assumed that the sales price could be set only at the beginning of the stage; demand is random and is a function of price; the highest price in finite and infinite period is the one where demand is zero. They also extended the model from single-stage to multi-stage. Other scholars have studied joint decision problem of stochastic demand/pricing ${ }^{[19-26]}$ in the single-stage. For example: Literature [21] considered simultaneous pricing and procurement decisions associated with a one-period pure inventory model under deterministic or probabilistic demand. It investigated the necessary and sufficient conditions for an $(\sigma, \Sigma)$ type policy to be optimal for the determination of the procurement quantity. How the corresponding optimal price could be obtained was also shown in this literature. Literature [24] explained the phenomenon of price rigidity (or price smoothing) as the outcome of the optimal inventory policy of a multi-period profit-maximizing firm under demand and output uncertainties. Price smoothing might be manifested in two forms. First, price changes might be moderated with respect to those implied by the demand function; and second, the firm might choose to restrict price fluctuations by establishing upper and/or lower bounds on prices. It showed that the extent of the asymmetry in price smoothing depends on the relationship between the inventory holding cost and the backlog penalty cost. The model accommodated a wide range of price behaviour as observed in empirical studies on the issue. The point of Literature [25] is that inventory adjustment attenuates downward pressure on price when realized demand is low because firms accumulate inventory holdovers, speculating that demand will be stronger in the succeeding period. When realized demand is high the firm draws down its inventories until a "stock-out" occurs and price rises to clear the market. Literature [26] addressed the simultaneous determination of pricing and inventory replenishment strategies in the face of demand uncertainty. More specifically, the single item, periodic review model was analyzed. Demands in consecutive periods were independent, but their distributions depend on the item's price in accordance with general stochastic demand functions. The price charged in any given period can be specified dynamically as a function of the state of the system. A 
replenishment order may be placed at the beginning of some or all of the periods. Stock-outs are fully backlogged. Both finite and infinite horizon models, with the objective of maximizing total expected discounted profit or its time average value were addressed, assuming that prices can either be adjusted arbitrarily (upward or downward) or that they can only be decreased. The structure of an optimal combined pricing and inventory strategy for all of the above types of models were characterized. An efficient value iteration method to compute these optimal strategies was also developed. Finally, an extensive numerical study that characterizes various qualitative properties of the optimal strategies and corresponding optimal profit values was made.

Early studies mainly focus on joint decision problem of dynamic storage/pricing under deterministic demand. Thomas ${ }^{[27]}$, Kunreuther and Schrage ${ }^{[28]}$ studied the joint decision problem of deterministic dynamic demand/pricing model in discrete-time based on the research of Wagner-Whitin ${ }^{[29]}$. Rajan, et al. ${ }^{[30]}$ extended discrete-time to the continuous time. He assumed the demand rate was a function of the price and time, and the price changed continuously in a complementary cycle, and is a function of time elapsed. The article discussed optimal pricing and storage strategies under the premise of assuming the supplement was in equal time intervals. Moreover, Elmaghraby and Keskinocak ${ }^{[31]}$ reviewed the research progress and practical application about the inventory decisions and dynamic pricing.

Our contributions to the literature and the management practice are: first, to proposing objective function based on sellers' maximize profits, and extending EOQ model to an optimal sales discounts decision model. Second, we also contribute by analyzing sellers' optimal price in an optimal sales discounts decision model. Third, proposed and proved propositions in this paper have certain practical significance.

\section{Sales discount decision problem with fixed order quantity}

The logical starting point of sales discount decision problem with Fixed Order Quantity is different from the previous EOQ problem. Suppliers' decisions are separated from sellers' in the previous research of EOQ decision. In fact, sellers' decisions rely on suppliers' decisions in most cases. In today's business in China, many suppliers especially some famous brand suppliers have raised the general requirements about procurement amount and procurement time for sellers, which make the relationship between the sellers' sales price and demand changes an important factors in EOQ model. It is an axiom that supply and demand determines the price. Most previous studies focus on this axiom, and overlook that sellers' sales prices also affect the demand. However, the latter is also unquestionable. The logical starting point of sales discount decision problem with Fixed Order Quantity is different from the previous EOQ problem. Suppliers' decisions are separated from sellers' in the previous research of EOQ decision. In fact, sellers' decisions rely on suppliers' decisions in most cases. In today's business in China, many suppliers especially some famous brand suppliers have raised the general requirements about procurement amount and procurement time for sellers, which make the relationship between the sellers' sales price and demand changes an important factors in EOQ model. It is an axiom that supply and demand determines the price. Most previous studies focus on this axiom, and overlook that sellers' sales prices also affect the demand. However, the latter is also 
unquestionable.

Literature [32] proposes two basic concepts, static pricing and dynamic pricing. The socalled static pricing refers to sellers set a unified retail price in finite period, and the demand rate is a deterministic function of the price. The so-called dynamic pricing refers to that sellers set sales prices at the beginning of each cycle in infinite period, and the demand rate is a deterministic functions of the price and time. These two concepts play a certain supporting role in introducing our questions in this paper. We have two research questions. First, how to make the best sales price decision or the best sales discount when the demand rate is deterministic and the order quantity is fixed? Second, in the presence of the total procurement amount and procurement time constraints, how to adjust the sales price of various kinds of goods to ensure that enterprises can obtain the maximize profits?

Literature [32] also extends the original discrete-time dynamic storage/pricing model to continuous time one, assuming that demands continuous change with time, and is a deterministic function of price, sellers set supplemental amount and goods prices in the initial stage of each replenishment cycle while, and in a replenishment cycle, the sales price is the same. The sales price is set to conditional one in this paper. The demand rate is determined by sales price in a finite stage. We also assumed that sellers make static pricing on earnings and flat goods, and make dynamic pricing on overstocked goods (i.e. inventory holdovers).

\subsection{Basic definitions and assumptions}

- The seller is a non-production retailer; does not provide non-physical products, such as services, no non-operating income.

- Business profits only determined by the amount of sales and the total cost.

- The total annual cost of inventories only constituted by the unit $\operatorname{cost}\left(C_{h}\right)$ and annual ordering cost $\left(C_{0}\right)$.

- The seller takes profit maximization as the goal.

- The cost parameters are greater than zero.

\subsection{Sales discount decision problem of single commodity with fixed order quantity in a single-stage}

First consider sales discount decision problem of single commodity with fixed order quantity in a single-stage. The target for the seller is to pursue the total annual maximum profit. Model assumptions are as follows,

- Demand is a linear function of the price i.e. $D=-k p+b$, where $D$ denotes the annual demand for the product, denotes the sales price of the goods; denote the slope and intercept of the linear function of demand respectively $(k>0, b>0)$.

- "Stock-out" is not allowed.

- The procurement quantity $Q>0$.

Total annual corporate profit will be obtained from the following general formula: 
Total annual profit $($ Profit $)=$ total annual sales - the total annual cost

$$
=p * D-1 / 2 * Q C_{h}-(D / Q) * C_{0}
$$

The total annual cost is the same as it in the classical EOQ model. Formula (2) can be obtained from (1),

$$
\text { Profit } \left.=p *(-k p+b)-1 / 2 Q C_{h}-((-k p+b) / Q) * C_{0}\right)
$$

Theorem 1 In a sales discount decision system of single commodity with fixed order quantity in a single-stage, optimum price must satisfy the following conditions,

$$
p^{*}=\left(b+k c_{0} / Q\right) / 2 k
$$

Proof Partial derivative of profit with respect to price is given as,

$$
\partial(\text { profit }) / \partial(p)=(-k p+b)+(-k p)-((-k p+b) / Q) * C_{0}=-2 k p+k C_{0} / Q+b
$$

Second order partial derivative of price with respect to price is given by,

$$
\frac{\partial^{2} \text { profit }}{\partial p^{2}}=-2 k \leq 0 .
$$

The optimum sales price which maximize the profit function under the revised EOQ with fixed ordering quantity system $\left(p^{*}\right)$ can be derived by taking the first order derivative with respect to $p$ of Equation (4) and setting it to zero, and is given by:

$$
\begin{gathered}
\partial(\text { profit }) / \partial(p)=-2 k p+k C_{0} / Q+b=0 \\
p^{*}=\left(b+k c_{0} / Q\right) / 2 k=C_{0} / 2 Q+b / 2 k
\end{gathered}
$$

Theorem 1 is proved.

Theorem 2 In a sales discount decision system of single commodity with fixed order quantity in a single-stage, when the annual ordering cost is constant, the optimal price depends only on the slope and intercept of the demand function. Intercept and the optimal pricing are proportional inverse; the slope and the optimal pricing are positively proportional.

Theorem 2 can be proved by Equation (6).

Theorem 3 It is more suitable for the commodity with a greater elasticity of demand to set a sales discount. In the premise of guaranteed profits, the price should not be less than the optimal price.

\subsection{Sales discount decision problem of multi-category goods with fixed order quantity in a single-stage}

In a sales discount decision problem of single commodity with fixed order quantity in a single-stage, we assume that order quantity is fixed. The assumption is still valid in this section $p_{i}(i=1,2, \cdots) . D_{i}$ denotes the price of commodities, i.e. $D_{i}=-k_{i} * p_{i}+b_{i}$.

Total annual profit is given by,

Total annual profit $($ Profit $)=$ total annual sales - the total annual cost

$$
=\sum_{i=1}^{n} p_{i} D_{i}-\frac{1}{2} Q C_{h}-\left(\sum_{i=1}^{n} D_{i} / Q\right) * C_{0}=\sum_{i=1}^{n} p_{i}\left(-k_{i} p+b\right)-\frac{1}{2} Q C_{h}-\left(\sum_{i=1}^{n}\left(-k_{i} p_{i}+b_{i}\right) / Q\right) * C_{0}(7)
$$


Theorem 4 In a sales discount decision system of multi-category goods with fixed order quantity in a single-stage, the optimal price of commodities in a single-stage must satisfy the following conditions,

$$
\sum_{i=1}^{n} k_{i} p_{i}^{*}=\frac{\left(\sum_{i=1}^{n} b_{i}+C_{0} / Q \sum_{i=1}^{n} k_{i}\right)}{2}
$$

Practical significance of theorem 3 is as follows, if the various types of products can be divided into the backlog of products, flat products and profitable products, the sales discount policy can be designed by sellers based on i.e. flat products and profitable products are not discounted, the backlog of products require a discount, then the research question is how much discount the backlog of products can be set is the optimal business decision. Assuming enterprise products are divided into three categories, Class 1 product is the profitable product, category 2 for the flat products, the third category is holdovers, then according to Theorem 3, i.e. $k_{1} p_{1}^{*}+k_{2} p_{2}^{*}+k_{3} p_{3}^{*}=\frac{b_{1}+b_{2}+b_{3}+C_{0} / Q\left(k_{1}+k_{2}+k_{3}\right)}{2}$; the optimal price of holdovers is $p_{3}^{*}=\left(\frac{b_{1}+b_{2}+b_{3}+C_{0} / Q\left(k_{1}+k_{2}+k_{3}\right)}{2}-\left(k_{1} p_{1}^{*}+k_{2} p_{2}^{*}\right)\right) / k_{3}$, assuming that prices of earnings classes and flat products have been similar to optimal price. The results for solving problems in reality are of great value.

\subsection{Sales discount decision problem of single commodity with fixed order quantity in a multi-stage}

Assumed further that

- In finite time, the time interval is $(0, H)$. Sales period in terms of years, starting point is not fixed.

- Fixed time of replenishment and fixed replenishment quantity constraints.

- Fixed replenishment costs in the various stages.

- The sales prices unchanged, in addition to the price of holdovers in various stages, $p_{h}=$ $d_{s} * p_{i}$, which $d_{s}$ is sales discount rate, $p_{h}$ denotes the price of holdovers, $p_{i}$ denotes the price of inventory.

- The backlog in the previous stage is taken as inventory in a later stage, namely $Q_{i}=$ $Q_{h}+Q_{r}$, which $Q_{i}$ denotes quantities of inventory, $Q_{h}$ denotes quantities of holdovers, $Q_{r}$ denotes quantities of replenishment.

- Demand functions are the same at each stage.

In a certain sales cycle $\left(t_{0}, t_{0}+1\right)$, then

Total annual sales $s=$ demand quantity for holdovers in the previous year's $*$ discounted price + sales price $*$ Demand quantity for other categories goods per year

$$
=P_{h} * \int_{t_{0}}^{t_{0}+1} D_{t} \mathrm{~d} t+p_{i} * \int_{t_{0}}^{t_{0}+1} D_{t} \mathrm{~d} t
$$

Total annual cost $=1 / 2\left(Q_{i}\right) * C_{h}+C_{0} *\left(\left(\int_{t_{0}}^{t_{0}+1} D_{t} \mathrm{~d} t\right) / Q_{r}\right)$, 
Total annual profit $($ Profit $)=$ total annual sales - the total annual cost

$$
=p_{h} * \int_{t_{0}}^{t_{0}+1} D_{t} \mathrm{~d} t+p_{i} * \int_{t_{0}}^{t_{0}+1} D_{t} \mathrm{~d} t-1 / 2\left(Q_{i} * C_{h}\right)+C_{0} *\left(\int_{t_{0}}^{t_{0}+1} D_{t} \mathrm{~d} t\right) / Q_{r}
$$

Wherein, $D_{t}=-k(t) p+b(t)$.

Theorem 5 In a sales discount decision system of single commodity with fixed order quantity in a multi-stage, if the regular price of such commodity is unchanged, its sales discount of holdovers should be given by

$$
d_{s}=\left(1-\frac{C_{0}}{Q_{r} * p_{r}}\right)
$$

Proof The first-order partial derivative with respect to time is given by

$$
\begin{aligned}
\frac{\partial(\text { profit })}{\partial(t)} & =p_{h} \int_{t_{0}}^{t_{0}+1} D_{t-1} \mathrm{~d} t+p_{i} * \int_{t_{0}}^{t_{0}+1} D_{t} \mathrm{~d} t-1 / 2\left(Q_{i} * C_{h}\right)-C_{0} *\left(\left(\int_{t_{0}}^{t_{0}+1} D_{t} \mathrm{~d} t\right) / Q_{r}\right)^{\prime} \\
& =d_{s} * p_{r}\left(D_{t_{0}}-D_{t_{0}-1}\right)+p_{i}\left(D_{t_{0}+1}-D_{t_{0}}\right)-\frac{C_{0}}{Q_{r}}\left(D_{t_{0}+1}-D_{t_{0}}\right) .
\end{aligned}
$$

The second-order partial derivative with respect to time is given by

$$
\begin{aligned}
\frac{\partial^{2} \text { profit }}{\partial t^{2}} & =d_{s} * p_{r}\left(D_{t_{0}+1}-D_{t_{0}}\right)^{\prime}+p_{r}\left(D_{t_{0}+1}-D_{t_{0}}\right)^{\prime}-\frac{C_{0}}{Q_{r}}\left(D_{t_{0}+1}-D_{t_{0}}\right)^{\prime} \\
& =d_{s} * p_{r}\left(D_{t_{0}}-D_{t_{0}-1}\right)^{\prime}+\left(p_{r}-\frac{C_{0}}{Q_{r}}\right)\left(D_{t_{0}+1}-D_{t_{0}}\right)^{\prime}
\end{aligned}
$$

Because $p_{r}>C_{0}$ and $Q_{r}>1$, therefore $p_{r}>\frac{C_{0}}{Q_{r} * p_{r}}$.

The coefficients in equation (11) are greater than 0 . Because $\left(D_{t}-D_{t-1}\right)<0$ and $\left(D_{t}-\right.$ $\left.D_{t-1}\right)^{\prime} \leq 0$. Therefore, the profit function has a maximum value. The formula (11) can be obtained when the maximum value is equal to zero,

$$
\begin{gathered}
\partial(\text { profit }) / \partial(t)=d_{s} * p_{r}\left(D_{t_{0}+1}-D_{t_{0}}\right)+p_{r}\left(D_{t_{0}+1}-D_{t_{0}}\right)-\frac{C_{0}}{Q_{r}}\left(D_{t_{0}+1}-D_{t_{0}}\right)=0 \\
d_{s}=\frac{\left(D_{t_{0}+1}-D_{t_{0}}\right)\left(1-\frac{C_{0}}{Q_{r} * p_{r}}\right)}{\left(D_{t_{0}+1}-D_{t_{0}}\right)}=\left(1-\frac{C_{0}}{Q_{r} * p_{r}}\right)
\end{gathered}
$$

Theorem 5 is proved.

It is of practical significance and easy for sellers to determine sales discount of holdovers in practice.

\subsection{Sales discount decision problem of multi-category goods with fixed order quantity in a multi-stage}

In section 2.3, the assumption of three products a little too strict, companies might be interested in this classification suspicious. In this section, when we expand the problem to the one with multi-product in multi-stage. The original mark $p$ to $p_{i}(i=1,2, \cdots)$ for $i$ class product prices will be revised as follows, first kind of demand for class product is denoted by $D_{i}\left(D_{i}=-k_{i}(t) p_{i}+b_{i}(t)\right)$.

Lemma 1 There must be a point in time which only one category goods is backlog among multi-category goods in finite time $(0, H)$. In a certain sales cycle $\left(t_{0}, t_{0}+1\right)$, there

Total annual sales $=$ demand quantity for holdovers in the previous year's $*$ discounted price 


$$
\begin{aligned}
& \quad+\text { sales price } * \text { Demand quantity for other categories goods per year } \\
& =p_{h} \int_{t_{0}}^{t_{0}+1} D_{j} t \mathrm{~d} t+\frac{\sum_{i=1}^{n-1} p_{i r}}{(n-1)} \int_{t_{0}}^{t_{0}+1} \sum_{i=1}^{n-1} D_{i t} \mathrm{~d} t, \\
& \text { Total annual cost }=\frac{Q_{i} C_{h}}{2}+\left(\int_{t_{0}}^{t_{0}+1} \sum_{i=1}^{n-1} D_{i t} \mathrm{~d} t\right) * c_{0} / Q_{r},
\end{aligned}
$$

Total annual profit $($ Profit $)=$ total annual sales - the total annual cost

$$
=p_{h} \int_{t_{0}}^{t_{0}+1} D_{j t} \mathrm{~d} t+\frac{\sum_{i=1}^{n-1} p_{i r}}{(n-1)} \int_{t_{0}}^{t_{0}+1} \sum_{i=1}^{n-1} D_{i t} \mathrm{~d} t-\frac{Q_{i} C_{h}}{2}-C_{0} *\left(\int_{t_{0}}^{t_{0}+1} \sum_{i=1}^{n-1} D_{i t} \mathrm{~d} t\right) / Q_{r}
$$

Theorem 6 In a sales discount decision system of multi-category goods with fixed order quantity in a multi-stage, if the regular price of such commodity is unchanged, its sales discount of holdovers should be given by

$$
d_{s}=\frac{\sum_{i=1}^{n-1}\left(D_{i t_{0}+1}-D_{i t_{0}}\right)\left(\bar{p}-\frac{C_{0}}{Q_{r}}\right)}{p_{j r} *\left(D_{j t_{0}+1}-D_{j t_{0}}\right)}
$$

Among them, $j$ denotes the backlog class, $p_{j r}$ as regular price of holdovers, $\bar{p}$ denotes the average price of other commodities.

Proof of Theorem 6 can be seen in the appendix.

\section{Case scenarios}

\subsection{Problem about optimal price}

Due to the good position in the bargain, some brands suppliers developed relatively harsh ordering conditions. The following parts is a problem about optimal price. Suppose a garment supplier requires the following conditions that its brand vendors must attend a required ordering each year, order quantity shall not be less than 300 pieces of items; A vendor ordering cost is 350 yuan, the average holding cost of goods is 60 yuan. Goods demand curve is . If the vendor has ordered 300 pieces of items, how much is the optimal price for the vendor which can maximize profits?

Solution: Use Theorem 1, can solve for

$$
p^{*}=\left(b+k c_{0} / Q\right) / 2 k=\frac{C_{0}}{2 Q}+\frac{b}{2 k}=\frac{350}{600}+\frac{1000}{10}=100.58 \mathrm{yuan},
$$

Maximum profit

$$
p * D-\frac{Q * C_{h}}{2}-\frac{D * C_{0}}{Q} \approx 300 \times 100-9000-350 \approx 20650 \text { yuan } .
$$

\subsection{Optimal sales discount for holdovers}

Continue 3.1 problems; Suppose the vendor operates have six categories of goods; The total order quantity is 300 pieces of items. The vendor has holdovers in this year due to the fixed order quantity per year. How much is the sales discounts of the holdovers in the next year, which can ensure the vendor to make maximum profits? Specific data is in Table 1.

According to data in Table 1, we can be found that there are backlogs in category B; the current backlogs are 39 pieces of items. According to Theorem 5, put the above data into equation (15). The following result can be obtained: 
Table 1 Data of vendor

\begin{tabular}{ccccc}
\hline Categories & Current demand & Current order & Demand in the next year & Average sales price \\
\hline$A$ & 34 & 35 & 69 & 260.22 \\
$B$ & 135 & 172 & 174 & 311.35 \\
$C$ & 5 & 5 & 1 & 372.13 \\
$D$ & 32 & 32 & 11 & 215.98 \\
$E$ & 26 & 31 & 17 & 221.52 \\
$F$ & 25 & 50 & 302.1 \\
\hline & $\sum_{i=1}^{n-1}\left(D_{i t_{0}+1}-D_{i t_{0}}\right)\left(\bar{p}-\frac{C_{0}}{Q_{r}}\right)$ & $=\frac{(274.39-350 / 300) *(35-4-21-9+25)}{p_{j r} *\left(D_{j t_{0}+1}-D_{j t_{0}}\right)} \approx$ & $(174-135) * 311.35$ &
\end{tabular}

At this point,

The maximum profit $=$ total annual sales - the total annual cost

$$
\begin{aligned}
& =0.591 * 100 * 39+274.39 *(69+1+11+17+50)-30 * 300-\frac{350 * 148}{300} \\
& =2304.9+40609-9000-172.67 \approx 33740.33 \text { yuan. }
\end{aligned}
$$

This result is of great significant; the results of this discussion will be launched in the next section.

\section{Discussions}

\subsection{Research implication of optimal sales discounts decision model}

Competition in the market can be seen as a game among the various economic agents. In a game played by suppliers and sellers, in most cases they will 'fight' (i.e. bargain), and seldom cooperate. Determination of sales discounts can be seen as sellers compromise to suppliers by seeking the optimal strategy with downstream customers. However, the determination of sales discount has long been considered to be a marketing problem, discount strategies often comes from an intuition of managers. This resulted in the certain operating risks. This study will prevent from managers' intuition. It improves decision-making process, and enables the process scientific by theoretical analysis and modeling.

As most of the non-linear model can be linearization, this study can be extended to optimal pricing or sales discounts research questions with respect to a function with complex demand. In this way, this paper will play a role in simplifying the practical problems. A complex pricing and demand data to fit the contents of the study can be processed by system identification model. The author will be discussed in detail elsewhere.

\subsection{Managerial implication of optimal sales discounts decision model}

According to the trend of observed data in section 3.2, we may believe that the price of goods in category B is prefer to be fixed because of a higher demand in the next period. The result in section 3.2 was interesting. The optimal sales discounts obtained, turned out to be less than $60 \%$ of the regular price. It seems to be unreasonable. But numerous managers in the actual operations are often doing like that. Do not forget, the supplier requires same procurement quantity of the vendors in the next period. That will make further holdovers of 
such goods, unless the demand in next period becomes larger. The possible gloomy result is very serious. In addition, it can also be found that in sales discounts optimization process, if the demand to other commodities is higher than that in previous period, the sales discount of holdovers can be smaller. Otherwise you will need a larger sales discount to enhance the sale and maximize profits.

This model has good openness, which can incorporate into various types of goods demand forecasts. To obtain the true and simplify demand function will be the next work should be done. Correct prediction to future demand will benefit to making a more favorable sales discount for the vendors. The model will help sales managers to make more scientific and effective decision-making in terms of the expanding aspects.

\section{Conclusions}

This paper summarizes the research results on basis of the practical issues. It develops some new sales discounts decision model closer to the actual situation based on the classical EOQ model. The results and the problems still existed are as follows.

\subsection{Single category of sales discounts decision problem}

This paper revised the assumption — vendors are always in the optimal state, in the existing literature of inventory system decision problems. First, we assumed that sellers only have one commodity; sellers can get maximum profit in a single stage by finding the optimal sales price. We prove that in a sales discount decision system of single commodity with fixed order quantity in a single-stage, when the annual ordering cost is constant, the optimal price depends only on the slope and intercept of the demand function. Intercept and the optimal pricing are proportional inverse; the slope and the optimal pricing are positively proportional. On this basis, sales discount decision problems single commodity in multi-stage is discussed. We further inference that the optimal sales discount is proportional to the elasticity of demand.

\subsection{Multi-category sales discount decision problem}

This paper draws on static pricing and dynamic pricing two classical concepts, starting from the actual situation, establishes a sales discount decision model with multi-category goods. With respect to sales discount decision system of multi-category goods in single-stage, we found basic conditions of optimal sales price for the holdovers in multi-category goods. By simplifying the optimal sales price calculated to specific value, a practical significance was given. With respect to sales discount decision system of multi-category goods in multi-stage, we first proposed a lemma, "There must be a point in time which only one category goods is backlog among multicategory goods in finite time $(0, H)$ ". Subsequently we proposed and proved conditions for sales discount of holdovers in a sales discount decision system of multi-category goods with fixed order quantity in a multi-stage. This model is more in line with China's market reality. It plays an important role in helping the sellers make their sales discount decision.

\subsection{Possible expansion direction in the future}

This paper presents and proves the conditions for the determination of the optimal sales discount, fully accounting of Michael Porter's diamond model. It will cause some difficulties for non-academic readers, since a number of elements in practice have been simplified to several 
important factors. In addition, the determination of the demand function does not source from the actual data directly. Although some examples of real data have been given, overall, how to do the exact setting of sales discount is still a question should be faced. Many related work to serve the sellers in reality should be done for the next stage-oriented (i.e. demand unknown stage) model.

In subsequent studies, the author are willing to conduct research work in demand forecasts, decision-making with the model, the integration of work, and a lot of the actual interaction between data and model validation, and model of the software with other scholars. We hope to realize intelligent data analysis and decision-making in reality.

\section{References}

[1] Harris F W. How many parts to make at once. Operations Research, 1990, 38(6): 947-950.

[2] Fazel F. A comparative analysis of inventory cost of JIT and EOQ. International Journal of Physical Distribution and Logistics Management, 1997, 27(8): 496-505.

[3] Fazel F, Fischer K P, Gilbert E W. JIT purchasing vs EOQ with a price discount: An analytical comparison of inventory costs. International Journal of Production Economics, 1998, 54(1): 101-109.

[4] Peterson R, Silver E A. Decision systems for inventory management and production planning. John Wiley and Sons, New York, 1979.

[5] Schonberger R J. A revolutionary way to streamline the factory. The Wall StreetJournal, $1982,15: 24$.

[6] Ray J, Chaudhuri K S. An EOQ model with stock-dependent demand, shortage, inflation and time discounting. International Journal of Production Economics, 1997, 53(2): 171-181.

[7] Charabarty T, Giri B C, Chaudhuri K S. An EOQ model for items with Weibull distribution deterioration, shortages and trend demand: An extension of Philip's model. Computers and Operations Research, 1998, 25(7): 649-658.

[8] Crowther J F. Rationale for quantity discounts. Harvard Business Review, 1964: 121-127.

[9] Hadley G, Whitin T M. Analysis of inventory systems. Prentice-Hall, Englewood Cliffs, NJ, 1963.

[10] Max A C, Candea D. Production and inventory management. Prentice-Hall, Englewood Cliffs, NJ, 1984.

[11] Banerjee A. A joint economic-lot-size model for purchaser and vendor. Decision Science, 1986, 17: $292-311$.

[12] Kim K H, Hwang H. Simultaneous improvement of supplier's profit and buyers cost by utilizing quantity discount. Journal of the Operational Research Society, 1989, 40: 255-265.

[13] Goyal S K, Cárdenas-Barrón L E. Note on: Economic production quantity model for items with imperfect quality-a practical approach. International Journal of Production Economics, 2002, 77(1): 85-87.

[14] Teng J T, Chang C T, Goyal S K. Optimal pricing and ordering policy under permissible delay in payments. International Journal of Production Economics, 2005, 97(2): 121-129.

[15] Whitin T M. Inventory control and price theory. Management Science, 1955, 2: 61-80.

[16] Mills E S. Uncertainty and price theory. Quarterly Journal of Economics, 1959, 73: $116-130$.

[17] Mills E S. Price, output, and inventory policy: A study in the economics of the firm and industry. New York: Wiley, 1962.

[18] Karlin S, Carr C R. Prices and optimal inventory policy, studies in applied probability and management science. Arrow K, Karlin S, Scarf H. Stanford University Press, Stanford, CA, 1962.

[19] Zabel E. Monopoly and uncertainty. Review of Economic Studies, 1970, 37: 205-219.

[20] Young L L. Price, inventory and the structure of uncertain demand. New Zealand Journal of Operational Research, 1978, 6: 157-177.

[21] Polatoglu L H. Optimal order quantity and pricing decisions in single period inventory systems. Internet Journal of Production Economics, 1991, 23: 175-185.

[22] Hempenius A L. Monopoly with random demand. Universitaare Pers Rotterdam, Rotterdam, the Netherlands, 1970.

[23] Lau A H, Lau H. The newsboy problem with price-dependent demand distribution. IIE Transactions, 1988, 20: $168-175$.

[24] Amihud Y, Mendelson H. Price smoothing and inventory[J]. The Review of Economic Studies, 1983, 50(1): $87-98$. 
[25] Reagan P B. Inventory and price behaviour. The Review of Economic Studies, 1982, 49(1): 137-142.

[26] Federgruen A, Heching A. Combined pricing and inventory control under uncertainty. Operations research, 1999, 47(3): 454-475.

[27] Thomas L J. Price and production decisions with random demand. Operations Research, 1974, 22: 513-418.

[28] Kunreuther H C, Schrage L. Joint pricing and inventory decisions for non-seasonal items. Econometrica, 1973, 39: 173-175.

[29] Wagner H M, Whitin T M. Dynamic version of the economic lot size model. Management Science, 1958, 5: 89-96.

[30] Rajan A, Rakesh A, Steinberg R. Dynamic pricing and ordering decisions by a monopolist. Management Science, 1992, 38(7): 240-262.

[31] Elmaghraby W, Keskinoca K P. Dynamic pricing in the presence of inventory considerations: Research overview, current practices, and future directions. Management Science, 2003, 49(10): 1287-1309.

[32] Yang T. A study on extensions for EOQ model and inventory pricing joint decision problems. Doctoral Dissertation of Xian Electronic Science and Technology University, 2005.

\section{Appendix}

Proof of Theorem 7

Proof The first-order partial derivative with respect to time is given by

$$
\begin{aligned}
\frac{\partial(\text { profit })}{\partial(t)}= & \left(p_{h} \int_{t_{0}}^{t_{0}+1} D_{j t} \mathrm{~d} t+\frac{\sum_{i=1}^{n-1} p_{i r}}{(n-1)} \int_{t_{0}}^{t_{0}+1} D_{i t} \mathrm{~d} t-1 / 2\left(Q_{i} * C_{h}\right)\right. \\
& \left.-C_{0} *\left(\int_{t_{0}}^{t_{0}+1} \sum_{i=1}^{n-1} D_{i t} \mathrm{~d} t\right) / Q_{r}\right)^{\prime} \\
= & d_{s} * p_{j r}\left(D_{j t_{0}+1}-D_{j t_{0}}\right)+\bar{p} \sum_{i=1}^{n-1}\left(D_{i t_{0}+1}-D_{i t_{0}}\right)-\frac{C_{0}}{Q_{r}} \sum_{i=1}^{n-1}\left(D_{i t_{0}+1}-D_{i t_{0}}\right) .
\end{aligned}
$$

The second-order partial derivative with respect to time is given by,

$$
\begin{aligned}
\frac{\partial^{2} \text { profit }}{\partial t^{2}} & =d_{s} * p_{r}\left(D_{t_{0}+1}-D_{t_{0}}\right)^{\prime}+\bar{p}\left(\sum_{i=1}^{n-1}\left(D_{i t_{0}+1}-D_{i t_{0}}\right)\right)^{\prime}-\frac{C_{0}}{Q_{r}} \sum_{i=1}^{n-1}\left(D_{i t_{0}+}-D_{i t_{0}}\right)^{\prime} \\
& =d_{s} * p_{j r}\left(D_{t_{0}+1}-D_{t_{0}}\right)^{\prime}+\left(\bar{p}-\frac{C_{0}}{Q_{r}}\right) \sum_{i=1}^{n-1}\left(D_{i t_{0}+1}-D_{i t_{0}}\right)^{\prime}
\end{aligned}
$$

because $\bar{p}>C_{0}, p_{j r}>C_{0}$ and $Q_{r}>1$, therefore $\bar{p}>\frac{C_{0}}{Q_{r}}$.

The coefficients in equation (16) are greater than 0 .

Because $\left(D_{t}-D_{t-1}\right)<0$ and $\left(D_{t}-D_{t-1}\right)^{\prime} \leq 0$, therefore, the profit function has a maximum value. The formula (16) can be obtained when the maximum value is equal to zero,

$$
\begin{gathered}
\partial(\text { profit }) / \partial(t)=d_{s} * p_{j r}\left(D_{t_{0}+1}-D_{t_{0}}\right)+\bar{p} \sum_{i=1}^{n-1}\left(D_{i t_{0}+1}-D_{i t_{0}}\right)-\frac{C_{0}}{Q_{r}} \sum_{i=1}^{n-1}\left(D_{i t_{0}+1}-D_{i t_{0}}\right)=0 \\
d_{s}=\frac{\sum_{i=1}^{n-1}\left(D_{i t_{0}+1}-D_{i t_{0}}\right)\left(\bar{p}-\frac{C_{0}}{Q_{r}}\right)}{p_{j r}\left(D_{j t_{0}+1}-D_{j t_{0}}\right)}
\end{gathered}
$$

Theorem 7 is proved. 